\title{
Annormally Large Wooden Foreign Body Impacted in the Rectosigmoid Golon without Bowel Perforation
}

\section{Arvinder Singh, Sohan Singh, Kamlesh Gupta, Ramesh Chander, Suman Bhagat \\ From the Department of Radiodiagnosis, Government Medical College, Amritsar, India.}

\section{Abstract:}

A 46 years old male presented with a history of assault and insertion of a long wooden object through his anus. Examination and radiological investigations of the patient revealed a $34 \times 4.0 \mathrm{~cm}$ long wooden object in the rectosigmoid colon. The foreign body was delivered by colotomy under general anesthesia.

Key words: Foreign Bodies, Colon, Anal Canal, Large Intestine, General Anesthesia.

\section{Introduction}

Intentional or unintentional insertion of rectal foreign bodies is not uncommon and often presents a serious challenge for the clinician. A variety of unusual foreign bodies have been reported introduced into the rectum like a stick, tumbler, pepper pot, screw driver, glass bottle, vibrator, door handles, electric bulb etc. for pleasure purposes or forces during the assault. These foreign bodies may cause perforations of sigmoid colon and rectum [1,2]. We present the case of a patient with a history of assault and insertion of a long wooden object through his anus.

\section{Case Report}

A 46 year married male was admitted in surgical OPD with complain of dull pain in anorectal region after alleged assault by robbers who forcibly inserted some elongated foreign body through his anal canal. He did not give history of any perverted sexual behavior. On per abdominal examination, a hard object was felt reaching above the umbilical region. A local examination showed slight redness in the perianal region. Per rectal examination showed the presence of irregular, hard wooden foreign body.

X-ray abdomen AP and lateral views, showed faintly radiopaque rod like a foreign body extending from the pelvic region and reaching up to the epigastric region. Few dilated air filled bowel loops were noted proximal to it. No evidence of free air under the domes or any signs of perforation were noticed [Fig. $1 a, b]$. Abdominal sonographic examination showed a large curvilinear hyperechoic object with dense posterior acoustic shadowing suggestive of some solid foreign body. No free fluid was seen in the peritoneal cavity [Fig.2].

Corresponding Author: Dr. Arvinder Singh

Email: arvinderdr@rediffmail.com

Received: May 24, 2013 | Accepted: June 6, 2013 | Published Online: June 30, 2013

This is an Open Access article distributed under the terms of the Creative Commons Attribution License (creativecommons.org/licenses/by/3.0)

Conflict of interest: None declared | Source of funding: Nil | DOl: http://dx.doi.org/10.17659/01.2013.0049 
Oral and intravenous contrast enhanced CT scan of the abdomen was highly diagnostic for exact site, size, location and nature of the foreign body. On axial and sagittal CT scans [Fig.3a-3d] a large well defined rod like abdominopelvic foreign body was seen in relation to the rectosigmoid colon and reaching up to the epigastric region causing marked stretching and elongation of the sigmoid colon. It measured about $34 \times 4.0 \mathrm{~cm}$ in size and showed central heterogeneous linear densities with -243 to $43 \mathrm{HU}$ in its substance. High attenuation area of about $245 \mathrm{HU}$ was seen at the periphery of the blunt upper end. Few dilated large bowel loops were seen proximal to the impacted foreign body. No evidence of any perforation or free peritoneal fluid was seen [Fig.4a,b].

Colotomy was done to deliver the foreign body. A large irregular rod like wooden foreign body was delivered [Fig.5a,b]. Endoscopic removal was avoided as it was quite large, was located high up in rectosigmoid region.

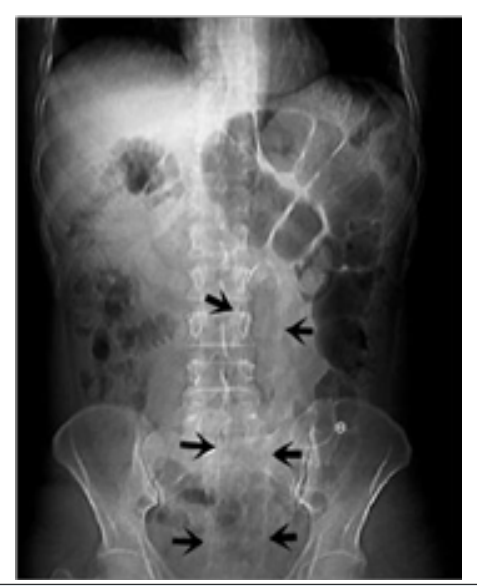

Fig.1: X-ray Abdomen (AP view) shows a faint radiopaque elongated rod like a foreign body in abdominopelvic regions (black arrows) with a rounded tip. Dilated air filled bowel loops are seen on the left side of abdomen.

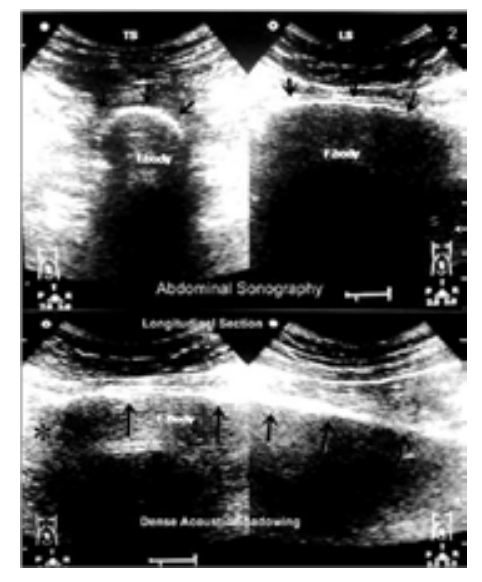

Fig. 2: Trans-abdominal sonography (curvilinearsectorprobe, $3.5 \mathrm{MHz}$ frequency) in transverse and longitudinal planes shows a large curviline a rechogenic structure (black arrows) with dense posterior acoustic shadowing obscuring the posterior abdominal structures. Blunt upper end of the foreign body is seen. 


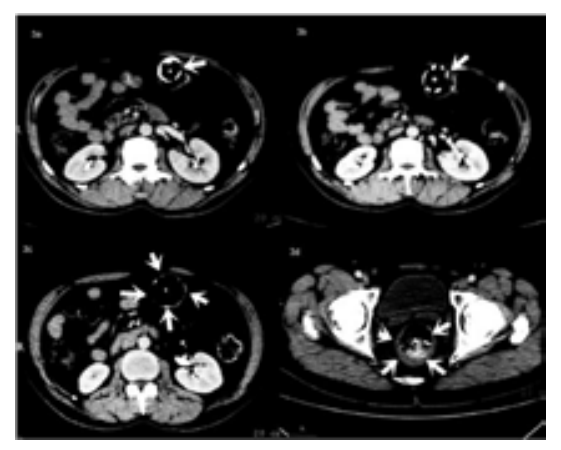

Fig.3: CECT abdomen (Philips Brilliance 6 slice scanner, $10 \mathrm{~mm}$ thick slice, oral and intra venous iodinated contrast) in axial planes ( $3 a-d)$ shows a round tooval foreign body filling the lumen of therec to sigmoid coloncausing circumferential thinning and stretching of the walls (white arrows). Central low attenuation areas areseen with iso to hyper attenuation margins

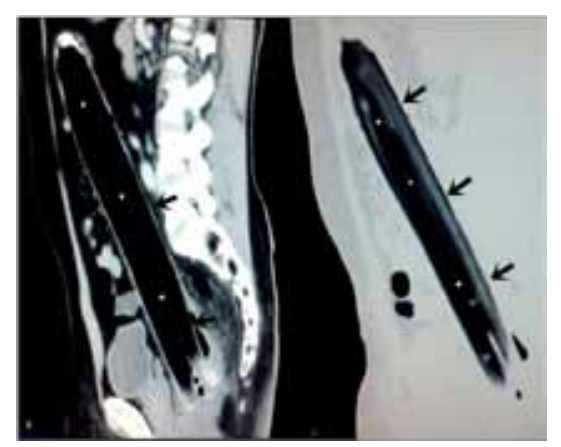

Fig.4: CECT abdomen (Philips Brilliance 6 slice scanner, $10 \mathrm{~mm}$ thick slice, oral and intravenous iodinated contrast $)$ in sagittal planes $(4 a, b)$ shows a large elongated foreign body filling and markedly stretching the lumen of the recto sigmoid colon with hyperdense blunt distal upper end (black arrows). Central linear heterogeneous areas of variable attenuation are due to wood fibers (4b). No sign of bowel perforation or free peritoneal fluid noted.

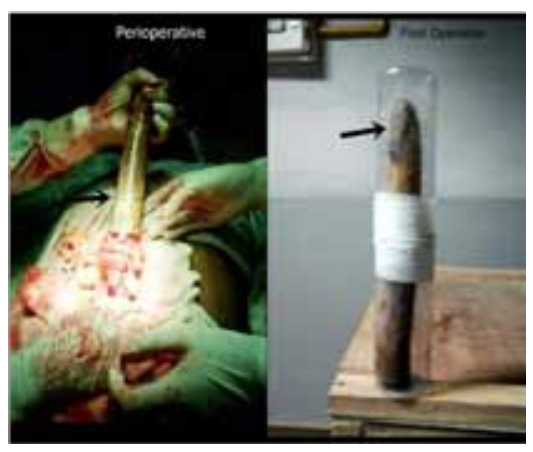

Fig.5: Perioperative photograph (5a) shows a large elongated club shaped wooden foreign body during colotomy. Post operative photograph (5b) shows the same foreign body in a sealed container (black arrow). 
Removal of such a large irregularly shaped foreign body could have caused multiple tears or laceration to the mucosal layer of the rectosigmoid colon. The patient recovered well after surgery and was discharged without any complications.

\section{Discussion}

The incidence of rectal foreign bodies varies according to region, said to be uncommon in Asia and more common in Eastern Europe. Rectal foreign bodies usually are inserted as a result of erotic activity. Still random cases of forcible insertions during assaults or tortures has been reported. Although retained rectal foreign bodies have been reported in patients of all ages, genders, and ethnicities, more than two-thirds of patients with rectal foreign bodies are men in their 30 s and $40 \mathrm{~s}[1,2]$.

Almost any object can be seen like candles, glass bottles, electric bulbs, vegetables, containers and odd or unusually large objects beer bottles, rods etc. Other causes for insertion include diagnostic or therapeutic purposes, self-treatment of anorectal disease, criminal assault and accidental $[3,4]$. Foreign bodies in the rectum in association with Munchausen's syndrome have been described in the literature [5].

Most patients with rectal foreign bodies present in the emergency department after futile efforts to remove the object at home. The first hand imaging in the evaluation of impacted rectal foreign bodies are $x$ rays and sonography [6]. An abdominal X-ray provides information on the location of the foreign body, whether it is below or above the rectosigmoid junction. Metal and glass objects are well visualized on plain radiograph

Table 1: Summary Table of Impacted Rectosigmoid Foreign Body

\begin{tabular}{|c|c|c|}
\hline Etiology & \multicolumn{2}{|c|}{ Forced insertion of $F B$ or for erotic activity } \\
\hline Gender ratio & \multicolumn{2}{|l|}{ Males > Females } \\
\hline Age predilection & \multicolumn{2}{|l|}{$30-40$ years } \\
\hline Risk factors & \multicolumn{2}{|c|}{$\begin{array}{l}\text { High type FB can cause perforation or impaction. Low lying FB can } \\
\text { cause abrasions and bruises. }\end{array}$} \\
\hline Treatment & \multicolumn{2}{|c|}{$\begin{array}{l}\text { The majority of rectal foreign bodies can be removed on an outpatient basis } \\
\text { transanally under local anesthesia. }\end{array}$} \\
\hline Prognosis & \multicolumn{2}{|c|}{ Overall prognosis good in non-complicated cases without perforation. } \\
\hline \multicolumn{3}{|c|}{ Imaging findings } \\
\hline$X$ ray & Ultrasound & CT Scan \\
\hline $\begin{array}{l}\text { Faint radio opaque } \\
\text { elongated foreign body } \\
\text { in abdominopelvic } \\
\text { region }\end{array}$ & $\begin{array}{l}\text { Large linear echogenic } \\
\text { structure with dense } \\
\text { posterior acoustic } \\
\text { shadowing }\end{array}$ & $\begin{array}{l}\text { Low attenuation rounded } \\
\text { structure with hyper dense } \\
\text { blunt end filling the lumen of } \\
\text { the rectum and sigmoid colon } \\
\text { with thinning and stretching } \\
\text { of the walls. }\end{array}$ \\
\hline
\end{tabular}


Table 2: Differential Diagnosis of Impacted Rectal Foreign Body

\begin{tabular}{|l|l|l|l|}
\hline Differential Diagnosis & X Ray & Ultrasound & CT Scan \\
\hline $\begin{array}{l}\text { Impacted Rectal } \\
\text { Erotic }\end{array}$ & $\begin{array}{l}\text { Faintly radio opaque } \\
\text { FB Body: For }\end{array}$ & $\begin{array}{l}\text { Echogenic structure } \\
\text { with dense posterior } \\
\text { acoustic shadowing }\end{array}$ & $\begin{array}{l}\text { FB with heterogeneous } \\
\text { areas of attenuation. }\end{array}$ \\
\hline $\begin{array}{l}\text { Mu n ch a u s n's } \\
\text { syndrome:Factitious } \\
\text { Psychiatric }\end{array}$ & $\begin{array}{l}\text { FB may or may not be } \\
\text { present }\end{array}$ & $\begin{array}{l}\text { Echogenic area in } \\
\text { rectal region. }\end{array}$ & $\begin{array}{l}\text { Localization of type } \\
\text { and density of foreign } \\
\text { body }\end{array}$ \\
\hline $\begin{array}{l}\text { Rapunzel Syndrome: } \\
\text { unusual gastric or rectal } \\
\text { trichobezoar }\end{array}$ & $\begin{array}{l}\text { May show mottled } \\
\text { appearances in } \\
\text { epigastric region. }\end{array}$ & $\begin{array}{l}\text { Echogenic area with } \\
\text { dense posterior } \\
\text { acoustic enhancement in } \\
\text { stomach, may reach } \\
\text { up to rectal region. }\end{array}$ & $\begin{array}{l}\text { Intraluminal mass with } \\
\text { mottled appearance } \\
\text { and heterogeneous } \\
\text { attenuation- Hair ball. }\end{array}$ \\
\hline
\end{tabular}

[Table 1,2]. Sonography helps in localization of the foreign body and complications like free peritoneal fluid. Artifacts however may hinder in diagnosis and exact nature of the object [7]. Computed tomography is an excellent modality for localization of foreign bodies especially partial or non radiodense objects situated high up in the abdomen and associated with complications [8].

Rectal foreign bodies can be classified as high-lying or low-lying depending on their location relative to the rectosigmoid junction. Objects above the sacral curve and rectosigmoid junction are difficult to visualize and should not be removed by rigid proctosigmoidoscope. Soft or low-lying objects could be grasped and removed safely in the emergency department. Foreign bodies in the rectum are known for potential complications like rectal bleeding, mucosal lacerations, anorectal pain, bowel perforations, abscesses and rarely death $[9,10]$. The majority of retained foreign bodies can be removed on an outpatient basis transanally under local anesthesia $[11,12]$. Laparotomy is required in high impacted foreign bodies and with associated complications like perforation [13].

The common differential diagnosis with associated abdominal or rectal FB are Munchausen's syndrome and Rapunzel Syndrome. Munchausen's syndrome is a factitious psychiatric disorder where the affected subject feigns disease in order to draw attention for sympathy. It is also sometimes known as hospital addiction syndrome or hospital hopper syndrome [5]. The Rapunzel syndrome is an unusual form of trichobezoar found in patients with a history of psychiatric disorders, trichotillomania (habit of hair pulling) and trichophagia (morbid habit of chewing the hair) consequently developing gastric bezoars [14].

\section{Conclusion}

Rectal foreign bodies present a difficult diagnosis and management. Delay in presentation together with multiple attempts at self-removal lead to mucosal edema and muscular spasms, further hindering removal. Most objects can be removed either manually or by using different instruments. Laparotomy is only required when 
there is a failure of transanal removal as in high or impacted foreign bodies.

\section{References}

1. Bhattacharya S, Pradhan L, Bhandari R, Jha R, Magar SP, Shrestha SK, Shrestha ML. Foreign body in the recto sigmoid colon. J Nepal Med Assoc. 2006;45: 249-251. PMID: 17189970

2. Akhtar MA, Arora PK. Case of unusual foreign body in the rectum. Saudi J Gastro Enteral. 2009;1 5:131 132. PMID: 19568580

3. Goldberg JE, Steele SR. Rectal foreign bodies. Surg Clin North Am. 2010;90:173-184. PMID: 20109641

4. Yaman M, Deitel M, Burul CJ, Shahi B, Hadar B. Foreign bodies in the rectum. Can J Surg. 1993;36:173177. PMID:8472230

5. Khan SA, Davey CA, Khan SA, Trigwell PJ, Chintapatla S. Munchausen's syndrome presenting as rectal foreign body insertion: A case report. Cases J. 2008;1:243. PMID:18925957

6. Eleonora Giorgini, Salomone Di Saverio, Andrea Biscardi, Silvia Villani, Nicola Clemente, Nicola Antonacci,Gregorio Tugnoli. Pandora's box: a threatening foreign body. BMJ Case Reports. $2011 ; 2011$. doi: $10.1136 /$ bcr.06.2010.3110. PMID:22701029

7. Sarai RK. Khandelwal AP, Morani AC, Ashtaker JL. Sonographic diagnosis of a glass foreign body in rectum. IJRI. 2006;16:549-551.

8. Gayer G, Petrovitch I, Jeffrey RB. Foreign objects encountered in the abdominal cavity at CT. Radio Graphics. $2011 ; 31: 409-428$. PMID:21415187

9. Desai B. Visual diagnosis: Rectal foreign body: A primer for emergency physicians. Int J Emerg Med. $2011 ; 4: 73$. PMID:22152071

10. Ruiz del Castillo J, Sellés Dechent R, Millán Scheiding M, Zumárraga Navas P, Asencio Arana F. Colorectal trauma caused by foreign bodies introduced during sexual activity: diagnosis and management. Rev Esp Enferm Dig. 2001;93:631-634. PMID: 11767487

11. Jatal SN. Colorectal foreign bodies and principles of its management. Ind Jour Surg. 1995;57:233-235.

12. Safioleas $M$, Stamatakos M, Safioleas $C$, Chatziconstantinou $C$, Papachristodoulou $A$. The management of patients with retained foreign bodies in the Rectum: from Surgeon with Respect. Acta Chir Belg. 2009; 109:352-355. PMID:19943592

13. Seung-Bum Ryoo, Heung-Kwon Oh, Heon-Kyun Ha, Eun Kyung Choe, Sang Hui Moon, Kyu Joo Park. Operative treatment with a laparotomy for anorectal problems arising from a self-inserted foreign body. J Korean Soc Coloproctol. 2012;28:56-60.

14. Roberto Lopes, Priscilla Sene Portel Oliveira, Eduardo Marcucci Pracucho, Marcelo Amade Camargo, João de Souza Coelho Neto, and Nelson Adami Andreollo, "The Rapunzel Syndrome: An Unusual Trichobezoar Presentation," Case Reports in Medicine, 2010, Article ID 841028, 3 pages, 2010. doi: $10.1155 / 2010 / 841028$. 